\title{
COPPOCK CATARACT AND CATARACTA PULVERULENTA CENTRALIS*
}

\author{
BY \\ Captain Emanuel Rosen, M.C. \\ NEWARK, N.J.
}

IN the Brit. Jl. of Ophthal., 1942, page 152, there appears an article entitled "Doyne's Discoid Cataract" (Coppock). The author had been asked to describe the slit-lamp appearance of this type of cataract and he proceeded to do so by stating the above mentioned cataract is a small biconvex opacity consisting of tiny spots looking " bright white in the beam of the lamp with a more or less clear central area." The " y's." could not be definitely identified; the opacity appeared to involve the embryonic nucleus only and to be of the nature of a very small lamellar cataract. The author also stated that since the originar report, ${ }^{1}$ cataracts have been found from time to time in cases having no connection with the Coppock family.

Duke-Elder ${ }^{2}$ states that this opacity may be granular or may be completely opaque. The opacity may also be situated in the embryonic or foetal nucleus, and it may vary considerably in size. The centre of the cataract may occasionally be clear. Frequently the opacity is associated with other opacities. The condition is considered rare and possesses a strong familial tendency. DukeElder recognizes that Coppock cataract and cataracta pulverulenta centralis first described by $\mathrm{Vogt}^{3}$ in 1922 are one and the same thing.

Nettleship in his original description stated the cataract was a flat sharply outlined disc lying between the nucleus and the posterior pole and always revealing a clear zone of cortex between it and the posterior capsule. Nettleship also stated that occasionally the cataract may show a triradiate marking which may connect it with the posterior " $Y$ " suture. (His illustration on pages 194-195, Fig. shows this cataract.) It is noteworthy that this author attempted to show consanguinity as a cause of this degeneracy(?) but the cataract was shown to appear in only one of the consanguineous marriages. In this original communication the author states that the opacity takes the shape of a sharply defined circular disc in which case a triradiate structure is evident. (Mrs. Packford, aged 24 years.) Two or three other cases show slight evidence of this rather indefinite triradiation. The usual cataract is about $4 \mathrm{~mm}$. wide, always bilateral and symmetrical.

\footnotetext{
* Received for publication, August, $19+4$.
} 
There is a whole series of gradations in the cataract from a fairly dense gray disc to a barely perceptible translucent opacity.

Ida Mann ${ }^{4}$ states that this type of cataract usually forms about the sixth month of foetal life; is probably due to a metabolic disorder and is related to lamellar cataract. It is also noteworthy that Ida Mann thinks this type of cataract requires further study and it is primarily for that reason that I wish to present some slitlamp photographs of this condition so that some further observations may be offered upon both its occurrence and its biomicroscopic appearance.

It is suggested that the name " Coppock" cataract is poorly chosen for, although the condition was first described in that family, it is quite evident that the same type of opacity was present in a great many unrelated people. This becomes evident when it is noted that there were several coloured patients amongst the twenty-four cases of this type of cataract seen in the past eighteen months. I had regarded these cases as " cataracta pulverulenta centralis" and to show their biomicroscopic appearance I have undertaken some special slit-lamp photographs.

The first case (Fig. 1) is a typical cataract of the type under discussion. The opacity is seen to occupy the most central portion of the lens with its centre being somewhat transparent. The disc itself is made up of tiny white highly refractile dot-like deposits

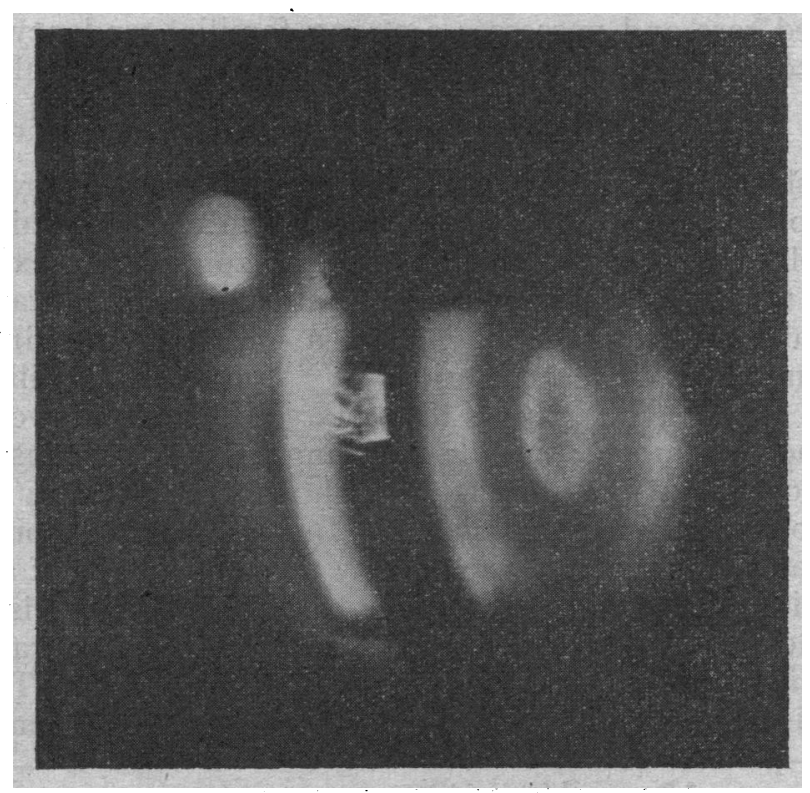

FIG. 1. (High power) 


\section{Coppock Cataract and Cataracta}

Pulverulenta Centralis

located in the foetal nucleus with only the lucid interval separating the anterior and posterior portions. The " $\mathrm{Y}$ " sutures are in this same zone and can be made out more or less incompletely. The disc appear's to have a greater posterior than anterior bulge. In some of the spaces between the small white dots are areas which resemble microscopic vacuoles seen in immature seńile cataract.

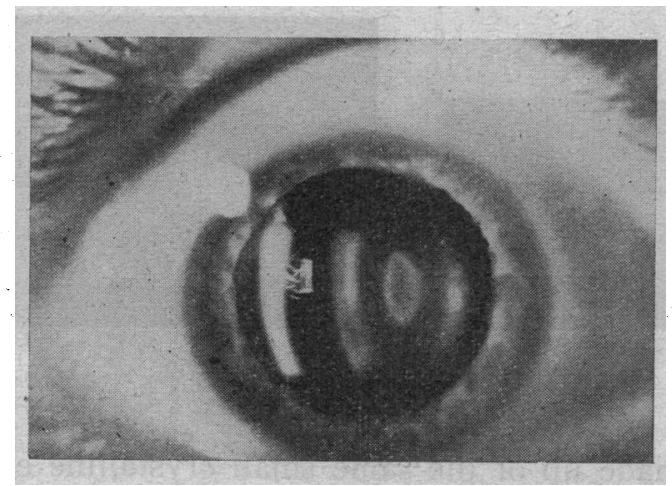

Fig. 1. (Low power)

Cataract depicted in Fig. 2 is very similar to that of Fig. 1 but the small white dots are more closely crowded and there is less reflection of light from these particles. There is a clear central interval and a clearer cortical area surrounding the disc. There

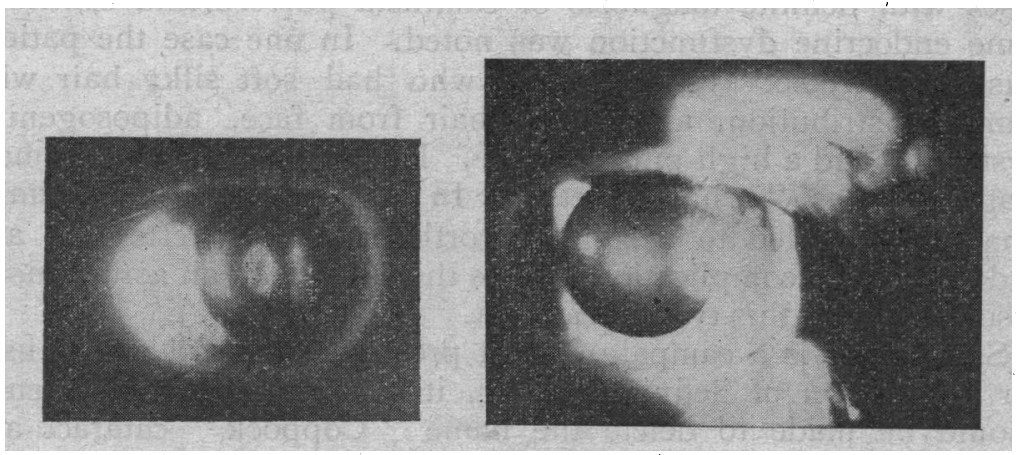

FIG. 2.

1

is no pronounced difference in the anterior and posterior curvature of the lens.

In the third case (Fig. 3) an antero-posterior view. shows the opacity to be approximately $2 \frac{1}{2} \mathrm{~mm}$. in diameter and again made up of the characteristic small white dots gathered within a circle. With the broad beam of the slit-lamp it is seen that the opacity is

(1)

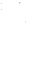


more spherical than disc-like. It is definitely not a flat disc. Again, there is a fairly clear central interval. This patient closely resembled an albino.

Fig. 4 is similar to the previously described cases although the opacity itself is somewhat smaller than Figs. 1, 2, 3. The cataract

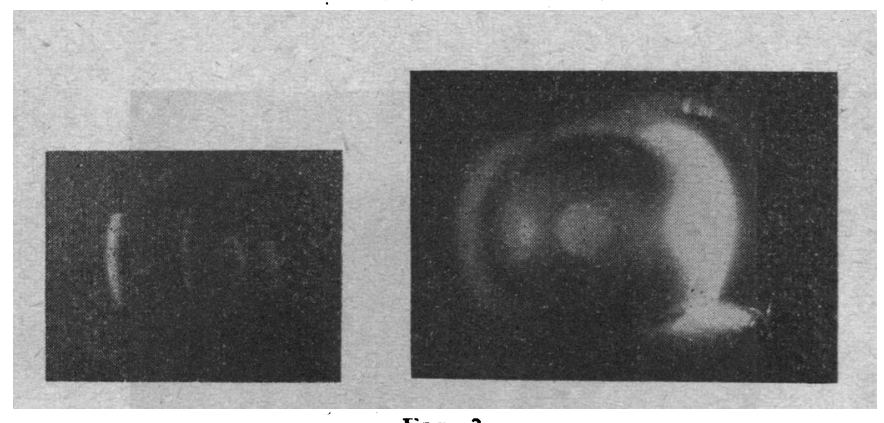

Fig. 3.

here too is made up of the same small crystalline elements. An interesting sidelight of this case was the "coupling" of camptodactyly with these cataracts, a condition which will be reported in more detail at a later date. In this same case there were also three small "spokes" just posterior to the opacity which; however, were not typically triradiate in arrangement.

It might be of some interest to point out that in three of these cases with definite diagnosis of cataracta pulverulenta centralis, some endocrine dysfunction was noted. In one case the patient was a-twenty-six year old male who had soft silky hair with female distribution, absence of hair from face, adiposogenital dystrophy and a high-pitched voice. In a second case the ultimate diagnosis was "renal rickets." In this case the congenitally small kidneys led to a series of orthopaedic, hypertensive and endocrinologic complications. The third case had an acrocyanosis associated with this type of cataract.

Since there is a campaign on at present to discard names used for description of definite entities, it appears that an attempt should be made to delete the name "Coppock" cataract and replace it by an anatomically selected term.

\section{REFERENCES}

1. NettleshiP and Ogilvie.-Trans. Ophthal. Soc. U.K., p. 191, 1906.

2. Text-book of Ophthalmology, Vol. II, p. 1368.

3. Vogt.-Arch.f. Ophthal., Vol. CVII, p. 235, 1922.

4. MANN, IdA.-Developmental Anomalies of the Eye. 